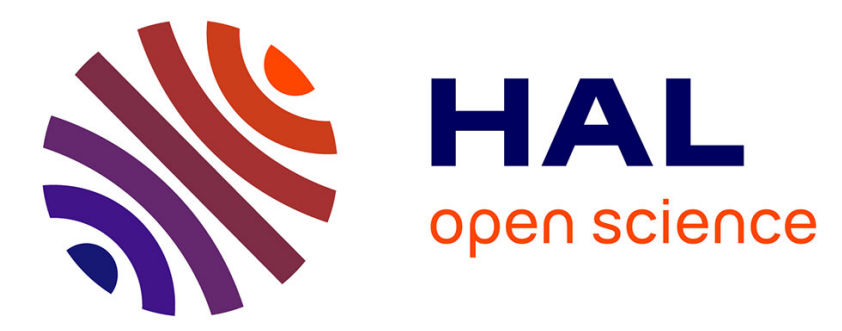

\title{
Solvothermal Temperature Drives Morphological and Compositional Changes through Dehydroxyfluorination in Anatase Nanoparticles
}

Wei Li, Monique Body, Christophe Legein, Olaf J. Borkiewicz, Damien

Dambournet

\section{To cite this version:}

Wei Li, Monique Body, Christophe Legein, Olaf J. Borkiewicz, Damien Dambournet. Solvothermal Temperature Drives Morphological and Compositional Changes through Dehydroxyfluorination in Anatase Nanoparticles. European Journal of Inorganic Chemistry, 2017, 2017 (1), pp.192-197. 10.1002/ejic.201601160 . hal-01427056

\section{HAL Id: hal-01427056 https: / hal.sorbonne-universite.fr/hal-01427056}

Submitted on 5 Jan 2017

HAL is a multi-disciplinary open access archive for the deposit and dissemination of scientific research documents, whether they are published or not. The documents may come from teaching and research institutions in France or abroad, or from public or private research centers.
L'archive ouverte pluridisciplinaire HAL, est destinée au dépôt et à la diffusion de documents scientifiques de niveau recherche, publiés ou non, émanant des établissements d'enseignement et de recherche français ou étrangers, des laboratoires publics ou privés. 


\section{Solvothermal Temperature Drives Morphological and Compositional changes through De-Hydroxyfluorination in Anatase Nanoparticles}

\begin{abstract}
Wei Li, ${ }^{[a]}$ Monique Body, ${ }^{[b]}$ Christophe Legein, ${ }^{[b]}$ Olaf
Abstract: The reaction system employing titanium alkoxide and hydrofluoric acid treated under solvothermal conditions has been widely used to prepare anisotropic anatase crystals featuring a large percentage of reactive $\{001\}$ facets. Nevertheless, such a reaction system yields to the stabilization of both fluoride and hydroxide substituting oxide in the anatase network. The presence of both anions is compensated by the stabilization of titanium vacancies. In this work, we demonstrated that the synthesis temperature impacts not only the morphology of the as prepared nanoparticles but also their chemical composition/structural features. Depending on the reaction temperature, two main crystal growth mechanisms that are anisotropic and/or driven by oriented attachment were observed. The morphological changes were associated with a variation of the composition. Particularly, high temperature allows to eliminate most of the $\mathrm{OH}$ groups through oxolation reactions but fluorine was shown to be thermally more stable as demonstrated by ${ }^{1} \mathrm{H}$ and ${ }^{19} \mathrm{~F}$ solidstate NMR spectroscopy. This work confirms that the above mentioned reaction system does not lead to pure titanium dioxide which is an important aspect in corroborating composition/morphological features to the physico-chemical properties.
\end{abstract}

Owing to its particular physico-chemical properties, titanium dioxide is currently investigated for a large set of applications ranging from photocatalysis to energy storage. ${ }^{[1]}$ Over the years, several approaches have been developed to modify/improve the properties of this compound. One of the current trends in solution-based processes is to employ morphology-controlling agent enabling the stabilization of highly reactive crystal facets featuring unique properties. ${ }^{[2]}$ In this field, a significant breakthrough was achieved in 2008 by Yang et al who have stabilized micrometer anatase single crystals with $47 \%$ of $(001)$ surface using hydrofluoric acid as a morphology-controlling agent. ${ }^{[3]}$ Anatase is one of the polymorphs of titanium dioxide and its name "anatase" derived from the Greek with the word " ana " = "elongated" which refers to the mineral crystal's shape. Using Wulff construction and calculated surface energies, the equilibrium shape of a $\mathrm{TiO}_{2}$ anatase crystal has been predicted

\footnotetext{
[a] Dr. W. Li, Dr. D. Dambournet.

Sorbonne Universités, UPMC Univ Paris 06, CNRS, Laboratoire PHENIX, Case 51, 4 place Jussieu, F-75005 Paris, France. E-mail: damien.dambournet@upmc.fr

[b] Dr. M. Body, Pr. C. Legein.

Université Bretagne Loire, Université du Maine, UMR CNRS 6283 , Institut des Molécules et des Matériaux du Mans (IMMM), Avenue Olivier Messiaen, 72085 Le Mans Cedex 9, France

[c] X-ray Science Division, Advanced Photon Source, Argonne National Laboratory, Argonne, Illinois, USA
}

Supporting information for this article is given via a link at the end of the document. to consist of a truncated octahedra which agrees with experimental observations. ${ }^{[4]}$ This crystal exposes only two types of surfaces with $96 \%$ of (101) and $4 \%$ of (001) surfaces. Calculations of surface energies indicate $0.44 \mathrm{~J} . \mathrm{m}^{-2}$ and 0.90 $\mathrm{J}^{\mathrm{m}} \mathrm{m}^{-2}$ for (101) and (001) surfaces, respectively, highlighting the highest stability for the (101) type surface. The difference of stability of the two types of surfaces has been explained in terms of density and nature of under-coordinated $\mathrm{Ti}$ species. The stable (101) surface exhibits $50 \%$ of titanium in a 6 -fold coordination mode and $50 \%$ of titanium in a 5 -fold coordination mode while the metastable (001) surface contains only 5 -fold coordinated $\mathrm{Ti}$ featuring enhanced interfacial properties. Such a difference in surface reactivity has led to extensive researches on the preparation of $\mathrm{TiO}_{2}$ crystals with specific facets. ${ }^{[2]}$

The presence of fluoride adsorbed on surfaces was shown to weaken the Ti-O bonds in (101) but strengthens them in (001), explaining the highest stability of the (001) for the F-adsorbed surfaces. ${ }^{[5]}$ Nevertheless, the possible presence of fluoride in the anatase's lattice has not been discussed in the literature so far. It is generally considered that fluoride anions are not stabilized within the anatase crystal lattice because $x$-ray diffraction patterns refer to " $\mathrm{TiO}_{2}$ " anatase and also because of inadequate characterization techniques, i.e. the fluorination is often characterized by x-ray photoelectron spectrometry (XPS) which probes only the surface of the particles. Recently, we showed that the reaction between titanium alkoxide and HF under mild solvothermal conditions leads to the stabilization of nanoparticles of anatase featuring an oxy-hydroxyfluoride composition $\mathrm{Ti}_{1-x-y} \square_{x+y} \mathrm{O}_{2-4(x+y)} \mathrm{F}_{4 x}(\mathrm{OH})_{4 y}$ where $\square$ represents titanium vacancies. ${ }^{[6]}$ The formation mechanism of this compound revealed that titanium alkoxide undergoes both hydrolysis and fluorolysis ("fluorolysis" was introduced by Kemnitz et $a^{\left({ }^{7,8]}\right)}$ yielding an anatase phase with an hydroxyfluoride composition which further evolved into an oxyhydroxyfluoride phase by oxolations reactions. ${ }^{\left[{ }^{9]}\right.}$ Moreover, the impact of the solvent characteristics and fluorine concentration has been investigated with respect to the structure/composition of the stabilized phases and were shown to be key parameters. ${ }^{[10]}$ Finally, increasing the reaction temperature (from 90 to $160^{\circ} \mathrm{C}$ ) induced the decrease of the titanium vacancies, i.e., the extent of the hydroxyfluorination, as revealed by realspace refinements of pair distribution function (PDF) data. ${ }^{[6]}$ Nevertheless, the reaction temperatures typically used in the literature commonly range from 150 to $200^{\circ} \mathrm{C} \cdot{ }^{[11-16]}$ In order, to understand how the temperature affects both the composition and the morphology of anatase nanoparticles, we systematically investigated both aspects in the reaction temperature range of $110-190{ }^{\circ} \mathrm{C}$. A good knowledge of the composition and the morphology is critical in controlling and modifying the reactivity of nanomaterials. 


\section{Results and Discussion}

It is generally believed that the reaction system employing titanium alkoxide, water and $\mathrm{HF}$ leads to the formation of $\mathrm{TiO}_{2}$ featuring 2D morphology with fluoride anions adsorbed on the surface. Our previous work showed that fluoride is actually incorporated within the anatase's lattice yielding the formation of titanium vacancies, i.e. $\mathrm{Ti}_{1-x-y} \square_{x+y} \mathrm{O}_{2-4(x+y)} \mathrm{F}_{4 x}(\mathrm{OH})_{4 y} \cdot{ }^{[6]}$ For a reaction temperature of $90{ }^{\circ} \mathrm{C}$, a time dependent study revealed that an hydroxyfluoride composition first formed and further evolved through a solid state transformation, to an oxyhydroxyfluoride phase by oxolation reactions. ${ }^{[9]}$ To understand the effect of the temperature on the reactivity of titanium alkoxide and $\mathrm{HF}$, a time-dependent study was performed at higher temperature, i.e., $\mathrm{T}=150^{\circ} \mathrm{C}$. Following our previous study, we employed high-energy synchrotron-based total scattering measurements and acquired data from which the PDF was obtained for samples prepared at different reaction times. PDF can be defined as a histogram of all the atom-atom distances obtained by Fourier transform of total scattering data (both diffuse and Bragg) and is therefore perfectly suited for characterization of amorphous/nanostructured materials. ${ }^{[17]}$ At the early stage of the reaction $(0.5 \mathrm{~h})$, the sample contains a small amount of amorphous $\mathrm{TiOF}_{2}$-like phase. Thereafter, samples are composed of a single phase of anatase. PDF data were refined against structural model based on the tetragonal symmetry of anatase using a real-space refinement (see experimental section). The PDF refinements are shown in Figure 1. The $\mathrm{Ti}(4 \mathrm{a})$ site occupancy was refined and the results are plotted as a function of the duration time (Figure 2). At the early stage of the reaction, a large content of titanium vacancies was obtained indicating the predominance of $\mathrm{OH}^{-}$and $\mathrm{F}^{-}$anions over $\mathrm{O}^{2-}$ in $\mathrm{Ti}_{1-x-y} \square_{x+y} \mathrm{O}_{2-4(x+y)} \mathrm{F}_{4 x}(\mathrm{OH})_{4 y}$ compounds. This indicates that titanium alkoxide readily reacted by hydrolysis and fluorolysis reactions which is similar to what was obtained at low temperature $\left(T=90^{\circ} \mathrm{C}\right) .{ }^{[9]}$ Thereafter, the vacancy content decreased progressively indicating a composition change upon reaction. Moreover, the particle size increased upon reaction. The morphological evolution of the particles with time was followed assuming a truncated octahedra, i.e., built from eight $\{101\}$ and two $\{001\}$ facets. ${ }^{[18]}$ Prolonging the reaction yields to an increase of the calculated percentage of exposed $\{001\}$ facets (Figure 2) highlighting an anisotropic crystal growth which differs from what occurs at $90^{\circ} \mathrm{C}$.

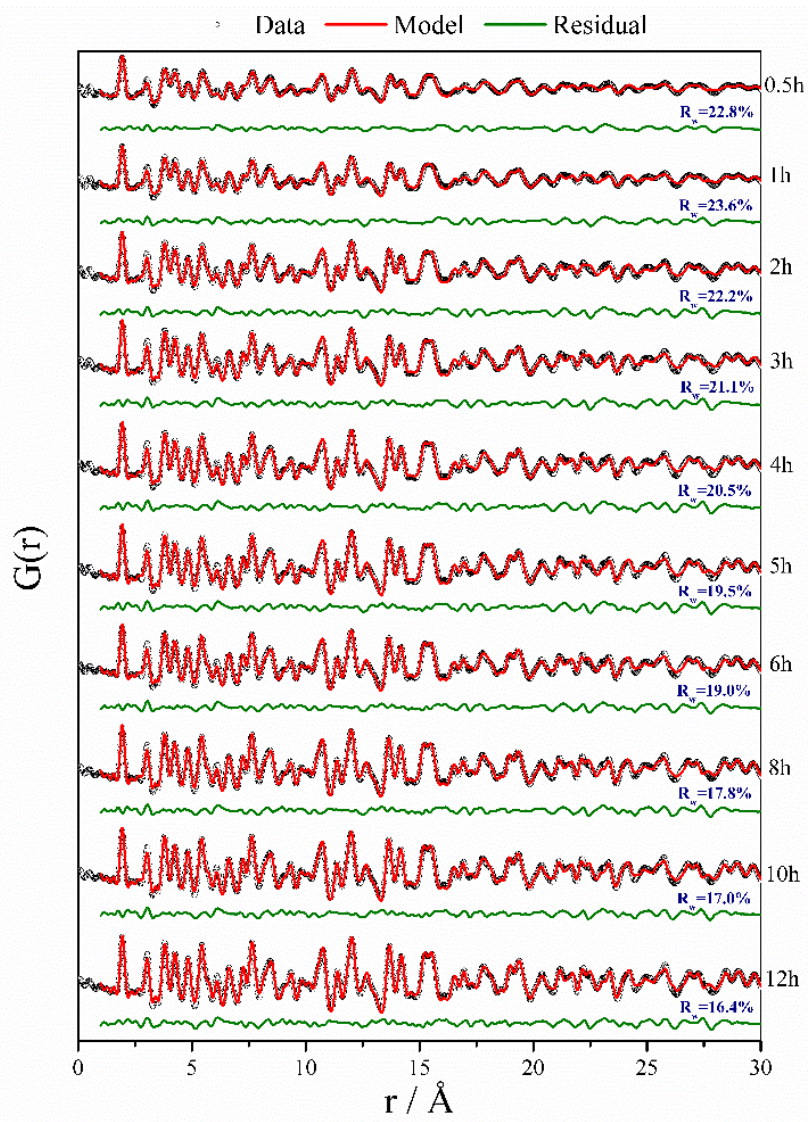

Figure 1. PDF refinements of the samples prepared at $150{ }^{\circ} \mathrm{C}$ at different reaction time.

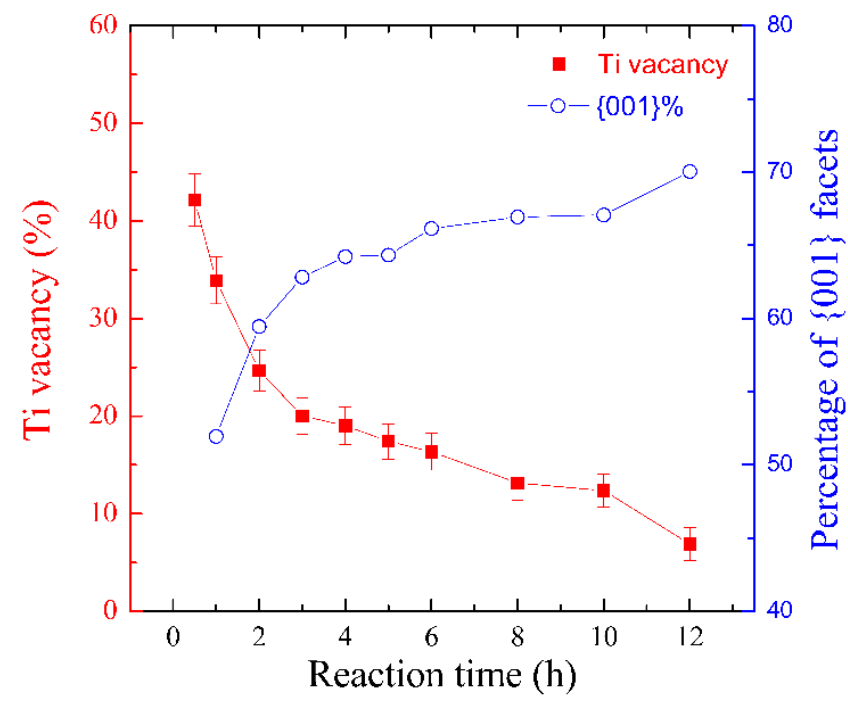

Figure 2. Evolution of the titanium vacancy concentration and the percentage of exposed $\{001\}$ facets upon reaction at $\mathrm{T}=150^{\circ} \mathrm{C}$. 
To examine the impact of the reaction temperature on the morphology, samples were prepared at different temperatures ranging from 110 to $190{ }^{\circ} \mathrm{C}$ for $12 \mathrm{~h}$. X-ray diffraction data confirmed the preparation of single phases of anatase (Figure S1 in supporting information).

The evolution of the average crystallite size (estimated using the Debye-Scherer equation based on the Full Width at Half Maximum (FWHM) of the (101) reflection) and the percentage of exposed $\{001\}$ facets are presented in Figure 3. On one hand, the average crystallite sizes gradually increased upon increasing the temperature, from $5 \mathrm{~nm}$ to about $19 \mathrm{~nm}$ for $\mathrm{T}=110$ and $190{ }^{\circ} \mathrm{C}$, respectively. On the other hand, the evolution of the percentage of exposed $\{001\}$ facets showed three distinct regions: (i) from 110 to $130^{\circ} \mathrm{C}$, the percentage of exposed $\{001\}$ facets remains constant to about $60 \%$, (ii) from 130 to $150{ }^{\circ} \mathrm{C}$, the percentage progressively increased to $70 \%$, (iii) from 150 to $190{ }^{\circ} \mathrm{C}$, the percentage remained constant at $70 \%$. Thus, depending on the temperature, crystal growth occurred via different mechanisms in this reaction system.

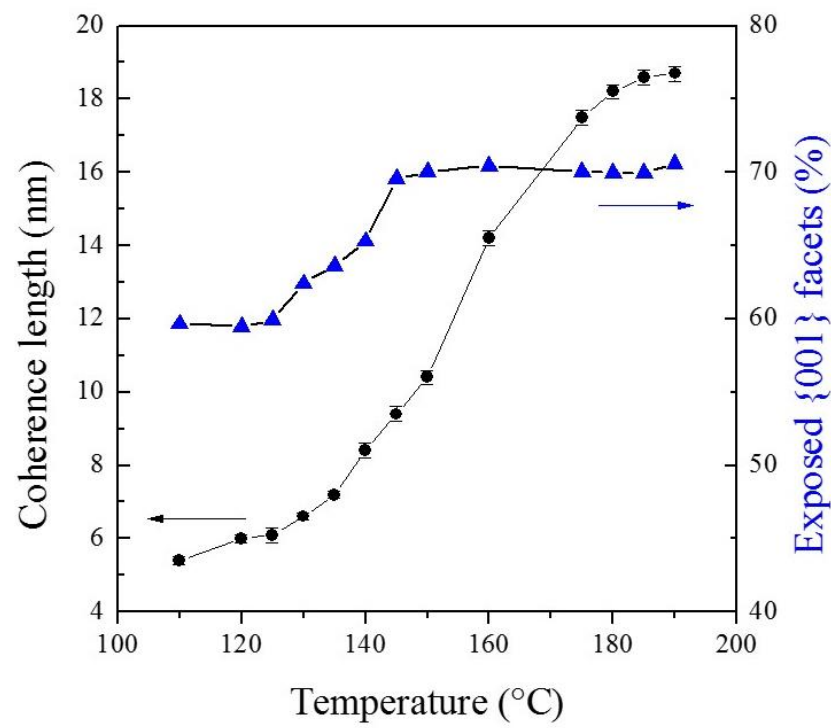

Figure 3. Evolution of the coherence length determined by using the DebyeScherrer equation and the percentage of exposed $\{001\}$ facets as a function of the reaction temperature. The duration time of the synthesis was set to 12 hours.

To understand the temperature-dependent crystal growth mechanism, transmission electron microscopy was conducted on selected samples prepared at 110,130, 150, 160, 175 and $190{ }^{\circ} \mathrm{C}$ (Figure 4). Table 1 gathers the morphological characteristics of the samples. As it can be observed, the temperature strongly impacts the morphology. The sample prepared at $110^{\circ} \mathrm{C}$ showed aggregated platelet-like particles with mean length of $11 \mathrm{~nm}$ and thickness of around $2 \mathrm{~nm}$. Upon increasing the reaction temperature up to $150{ }^{\circ} \mathrm{C}$, the platelet like aspect of the particles become more pronounced as shown by the increase of the aspect ratio highlighting an anisotropic growth of the particles. At $\mathrm{T}>150^{\circ} \mathrm{C}$, both the side length and the thickness of the particles increase (the aspect ratio decreases) showing that the growth process becomes more isotropic. Moreover, at $\mathrm{T}>150^{\circ} \mathrm{C}$, we observed the presence of Moiré patterns which are due to the interference between the crystalline lattices as emphasized in Figure 3 by dotted circles. This indicates that stacking of particles occurs along a similar direction, (001), and suggests that the crystal growth follows an oriented attachment (OA) mechanism. ${ }^{[11]}$ Indeed, in such a mechanism, the interface of two stacked particles re-arrange and fuse to form a crystal two times thicker than the original ones. Strikingly, the percentage of exposed $\{001\}$ facets remains constant after $150{ }^{\circ} \mathrm{C}$ showing that both $\mathrm{OA}$ and anisotropic growth occur concomitantly.
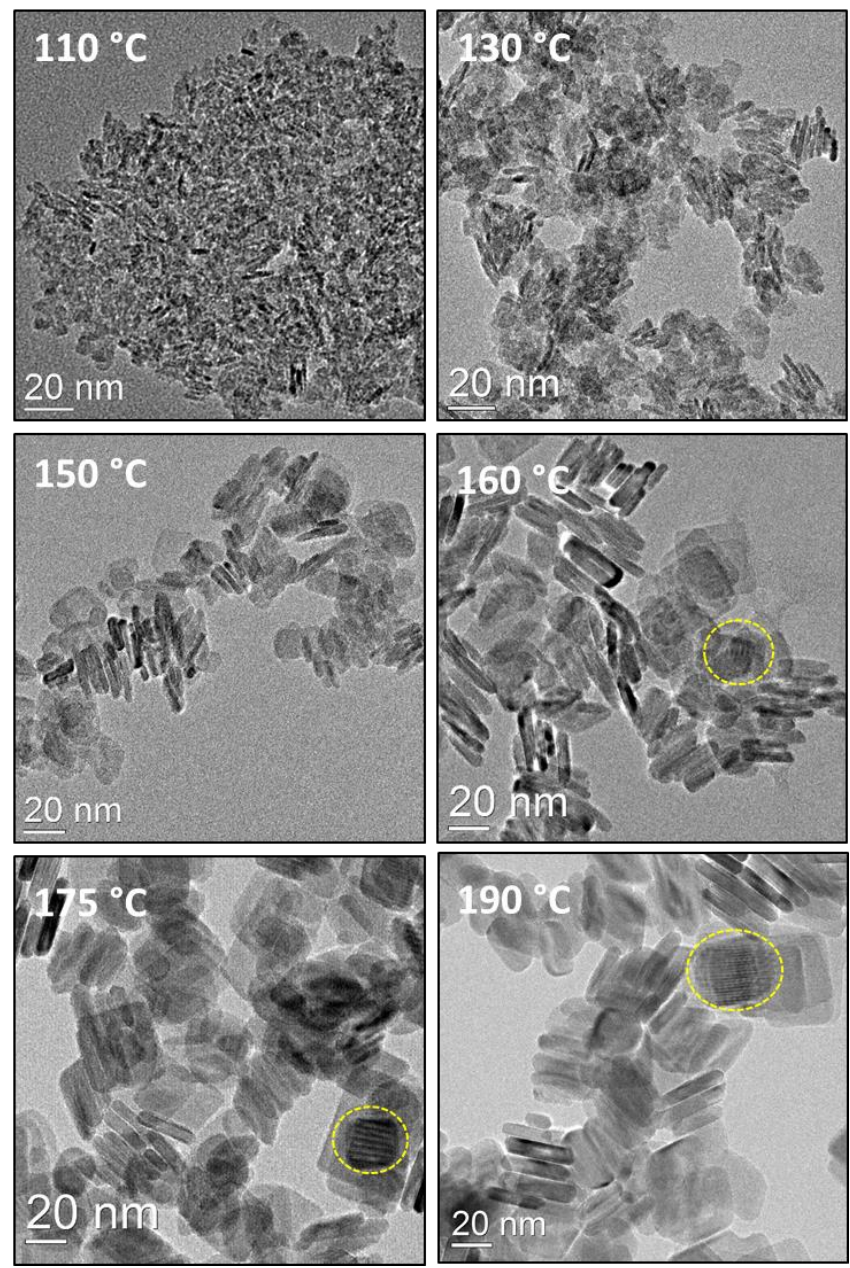

Figure 4. Transmission electron microscopy images of temperaturedependent anatase nanoparticles. Yellow dotted circles in panel mark Moiré patterns. 
Table 1. Morphological characteristics of samples prepared at different temperatures.

\begin{tabular}{lllll}
\hline $\begin{array}{l}\text { Synthesis } \\
\begin{array}{l}\text { Temperature } \\
\left({ }^{\circ} \mathrm{C}\right)\end{array}\end{array}$ & $\begin{array}{l}\text { Particle } \\
\text { length }(\mathrm{nm})\end{array}$ & $\begin{array}{l}\text { Thickness } \\
(\mathrm{nm})\end{array}$ & $\begin{array}{l}\text { Aspect } \\
\text { ratio }^{\mathrm{aa}]}\end{array}$ & $\begin{array}{l}\% \\
\text { exposed } \\
\text { [001\} facets }\end{array}$ \\
\hline 110 & $11 \pm 3$ & $2 \pm 0.5$ & 5.5 & 60 \\
130 & $15 \pm 3$ & $2.5 \pm 0.3$ & 6.0 & 62 \\
150 & $22 \pm 3$ & $3.6 \pm 0.5$ & 6.1 & 70 \\
160 & $28 \pm 5$ & $4.7 \pm 0.8$ & 5.9 & 70 \\
175 & $32 \pm 6$ & $6.2 \pm 1$ & 5.1 & 70 \\
190 & $34 \pm 6$ & $7 \pm 1$ & 4.9 & 70 \\
\hline
\end{tabular}

[a] obtained by dividing the particle length by the thickness.

The OA mechanism was further evidenced by the visualization of holes/gaps that are due to incomplete surface fusion between nanoparticles (Figure 5). Moreover, the measured interplanar distance of $0.235 \mathrm{~nm}$ shows that the OA mechanism proceeds along the [001] direction which agrees with literature data. ${ }^{[11]}$

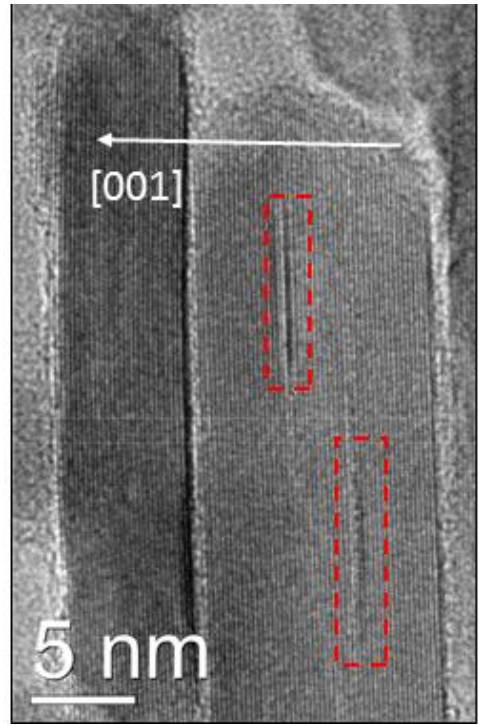

Figure 5. High-resolution TEM image of the samples prepared at $190^{\circ} \mathrm{C}$. Red dotted rectangles shows the holes/gaps within a particle.

In the following, the impact of the synthesis temperature on the chemical composition was studied. According to Yang et al who investigated the "Hydrothermal Stability of $\{001\}$ Faceted Anatase $\mathrm{TiO}_{2}$ ", the $\mathrm{OA}$ mechanism is driven by the modification of the surface composition. ${ }^{[11]}$ The hydrolysis of fluorine bonded to the surface allows further condensation of $\mathrm{OH}$ groups to form oxo bridges in the newly formed crystal. The aforementioned results showed that $\mathrm{OH}$ groups and fluorine atoms are also present in the bulk. Therefore, ${ }^{1} \mathrm{H}$ and ${ }^{19} \mathrm{~F}$ solid-state MAS NMR spectroscopies were used to understand the composition changes occurring upon increasing the reaction temperature.

Fluorine was quantified by ${ }^{19} \mathrm{~F}$ NMR (see experimental section) for samples prepared at different temperatures (Figure 6). At $110^{\circ} \mathrm{C}$, the sample contains a large amount of fluorine, i.e. 10.1 wt \%, emphasizing a large content of titanium vacancies. Upon increasing the reaction temperature, the fluorine weight percentage largely decreases to $5 \mathrm{wt} \%$ at $160^{\circ} \mathrm{C}$. Strikingly, at T $=190{ }^{\circ} \mathrm{C}$, the fluorine content still reached around $4 \mathrm{wt} \%$. It should be noted that the titanium vacancies content is too low to be detected by PDF refinements. Nevertheless, ${ }^{19} \mathrm{~F}$ solid state NMR was shown to be a suitable probe to identify the presence of titanium vacancies. ${ }^{[6,9,10]}$

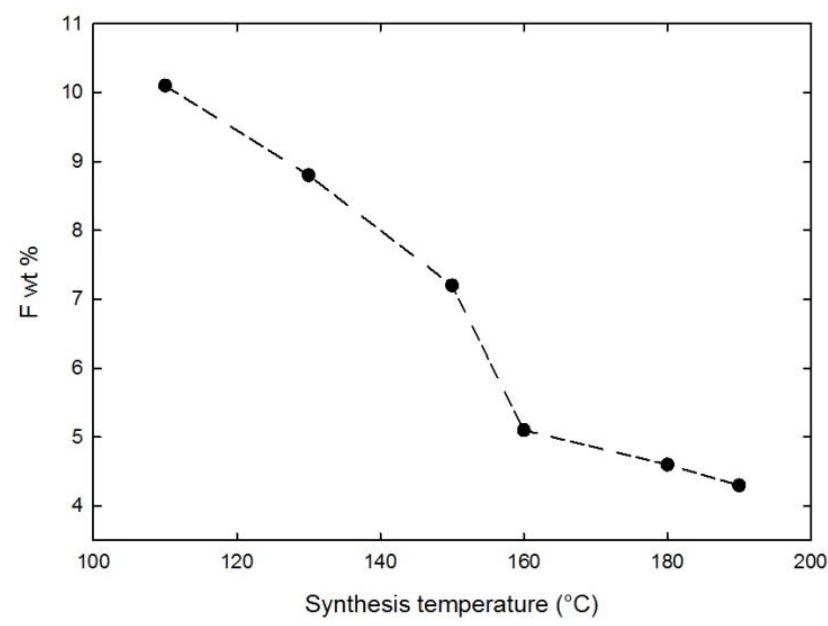

Figure 6. Fluorine weight percent as a function of the synthesis temperature.

${ }^{19} \mathrm{~F}$ MAS NMR non-normalized spectra of samples prepared at different temperatures are shown in Figure 7. The fits of these spectra (Figure S2-S7, Table S1-S6) and the masses of each sample in the rotor are given as supporting information. All spectra show three distinct lines which have been previously assigned in anatase $\mathrm{Ti}_{0.78} \square_{0.22} \mathrm{O}_{1.12} \mathrm{~F}_{0.4}(\mathrm{OH})_{0.48}$ to $\mathrm{Ti}_{3}-\mathrm{F}$ (-88 ppm), $\mathrm{Ti}_{2} \square-\mathrm{F}(-4 \mathrm{ppm})$ and $\mathrm{Ti}_{2}-\mathrm{F}(98 \mathrm{ppm})$ species. ${ }^{[6]}$ These three fluorine environments clearly demonstrate the presence of titanium vacancies in these $\mathrm{Ti}_{1-x-y} \square_{x+y} \mathrm{O}_{2-4(x+y)} \mathrm{F}_{4 x}(\mathrm{OH})_{4 y}$ samples. Due to the decrease of the amount of fluorine the integrated intensities of all the ${ }^{19} \mathrm{~F}$ NMR lines decrease upon increasing the reaction temperature. Moreover, the relative intensities of the ${ }^{19} \mathrm{~F}$ NMR lines assigned to the species $\mathrm{Ti}_{3}-\mathrm{F}$ (from $\sim 4 \%$ to $\sim 6 \%$ ) and $\mathrm{Ti}_{2} \square-\mathrm{F}$ (from $\sim 60 \%$ to $\sim 65 \%$ ) increase whereas the relative intensities of the ${ }^{19} \mathrm{~F}$ NMR lines assigned to the species $\mathrm{Ti} \square_{2}-\mathrm{F}$ (from $\sim 36 \%$ to $\sim 29 \%$ ) decrease when the reaction temperature increases (Figure S9). Finally, as shown by the decrease of the line widths of the ${ }^{19} \mathrm{~F}$ NMR lines, the disorder around the fluorine atoms decreases upon increasing the reaction temperature. 


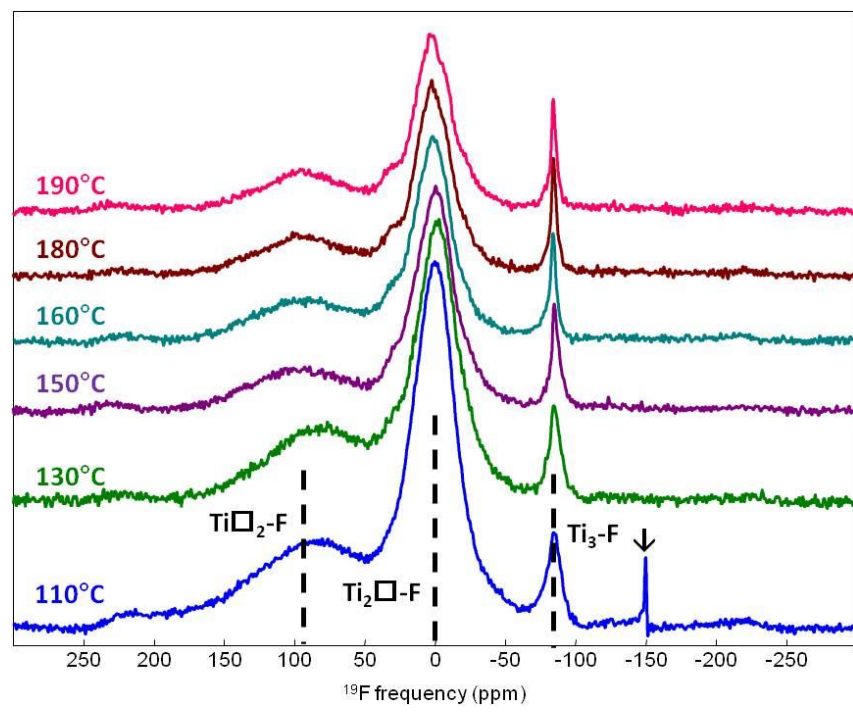

Figure 7. ${ }^{19} \mathrm{~F}$ MAS $(64 \mathrm{kHz})$ solid state NMR spectra of samples prepared at different temperatures. The dashed lines indicate the three main lines assigned to $\mathrm{Ti}_{3}-\mathrm{F}, \mathrm{Ti}_{2} \square-\mathrm{F}$ and $\mathrm{Ti} \square_{2}-\mathrm{F}$ environments. The arrow indicates an unidentified impurity.

${ }^{1} \mathrm{H}$ MAS NMR non-normalized spectra of samples prepared at different temperatures are shown in Figure 8. The fits of these spectra (Figure S9-S11, Table S7-S9) and the masses of each sample in the rotor are given as supporting information. The intensities of the proton resonances markedly decrease upon increasing the reaction temperature (by about $60 \%$ between $\mathrm{T}=$ $110^{\circ} \mathrm{C}$ and $\mathrm{T}=190{ }^{\circ} \mathrm{C}$ ) in agreement with a decrease of the titanium vacancies. Spectra have been fitted with three (or four) distinct NMR resonances one at $1.2 \mathrm{ppm}$, one at $\sim 4 \mathrm{ppm}$ and one (or two) broader one(s) in the range 6.7-7.9 ppm. Crocker et al assigned in anatase signals observed at 2.3 and $6.7 \mathrm{ppm}$ to terminal and bridging $\mathrm{OH}$ groups, respectively. ${ }^{[19]}$ This suggests that chemical shift values increase upon increasing the number of $\mathrm{Ti}$ surrounding $\mathrm{OH}$ groups. Similarly to fluorine environments, three different environments are expected based on the number of surrounding titanium and vacancy which are $\mathrm{Ti}_{3}-\mathrm{OH}, \mathrm{Ti}_{2} \square-\mathrm{OH}$ and $\mathrm{Ti}_{2}-\mathrm{OH}$. The NMR resonances at $1.2 \mathrm{ppm}, \sim 4 \mathrm{ppm}$ and in the range 6.7-7.9 ppm are therefore tentatively assigned to $\mathrm{Ti} \square_{2}-\mathrm{OH}, \mathrm{Ti}_{2} \square-\mathrm{OH}$ and $\mathrm{Ti}_{3}-\mathrm{OH}$ species, respectively. The relative intensities of these NMR resonances point out that $\mathrm{OH}$ groups preferentially formed $\mathrm{Ti}_{2}-\mathrm{OH}$ and $\mathrm{Ti}_{3}-\mathrm{OH}$ species. This agrees with the preferential location of fluorine in single vacancy system, i.e., $\mathrm{Ti}_{2} \square$-F. Moreover, the tentative assignment of the ${ }^{1} \mathrm{H}$ NMR resonances is supported by the variations of their proportions since the relative intensities of the ${ }^{1} \mathrm{H}$ NMR lines assigned to the species $\mathrm{Ti}_{2} \square-\mathrm{OH}$ (from $37 \%$ to $13 \%$ ) and $\mathrm{Ti}_{2}{ }_{2}$ $\mathrm{OH}$ (from $\sim 6 \%$ to $\sim 4 \%$ ) decrease whereas the relative intensities of the ${ }^{1} \mathrm{H}$ NMR lines assigned to the species $\mathrm{Ti}_{3}-\mathrm{OH}$ (from $~ 57 \%$ to $\sim 83 \%$ ) increase when the reaction temperature increases, that is, when the titanium vacancy rate decreases.

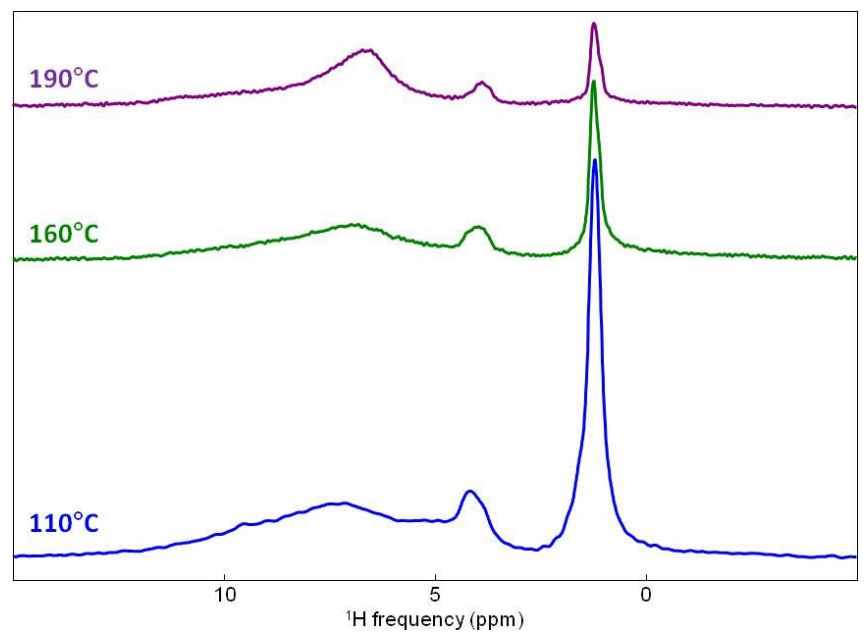

Figure 8. ${ }^{1} \mathrm{H}$ MAS $(64 \mathrm{kHz})$ solid state NMR spectra of samples prepared at different temperatures.

Overall, this work shows that the temperature largely impacts both the composition and the morphology of the nanoparticles. The reaction system used in this study including titanium alkoxide and HF is similar to other studies and therefore the results obtained are likely applicable to others. Particularly, the presence of fluoride and hydroxide anions associated with titanium vacancies was shown to be present even at high temperature. The study of the mechanism of formation at $150^{\circ} \mathrm{C}$ points out a rapid hydrolysis and fluorolysis of the titanium alkoxide. Increasing the reaction temperature was shown to decrease the titanium vacancies's content highlighting a dehydroxyfluorination according to:

$\mathrm{Ti}_{1-x-y} \square_{x+y} \mathrm{O}_{2-4(x+y)} \mathrm{F}_{4 x}(\mathrm{OH})_{4 y} \rightarrow(1-x-y) \cdot \mathrm{TiO}_{2}+4 \mathrm{x} \cdot \mathrm{HF}+2(\mathrm{y}-\mathrm{x}) \cdot \mathrm{H}_{2} \mathrm{O}$ Nevertheless, the above reaction was shown to be incomplete even at high temperature and the chemical processes tend to favor the stabilization of an oxyfluoride-based composition.

In addition to a structural re-arrangement inducing a compositional change, the temperature was shown to modify the morphology of the nanoparticles. Our study showed that two sets of temperature range can be distinguished. Up to $150{ }^{\circ} \mathrm{C}$ anisotropic crystal growth was observed with mean length and thickness ranges of 11-22 and 2-3.6 nm, respectively. At T> $150{ }^{\circ} \mathrm{C}$, both anisotropic and oriented attachment crystal growth occurred yielding mean length and thickness ranges of 22-34 and 3.6-7 nm, respectively. This study provides complementary information on how to control the aspect ratio of $2 \mathrm{D}$ nanocrystals of anatase. ${ }^{[11]}$

\section{Conclusions}

Using the reaction system based on titanium alkoxide, water and $\mathrm{HF}$, we have investigated the effects of the reaction temperature on the composition and morphological aspects of anatase nanoparticles. We demonstrated that in the temperature range of 90 to $190{ }^{\circ} \mathrm{C}$, the prepared anatase contained both fluoride and hydroxide substituting oxide anions compensated by the 
formation of titanium vacancies. ${ }^{1} \mathrm{H}$ and ${ }^{19} \mathrm{~F}$ solid-state NMR spectroscopy clearly demonstrated the presence of titanium vacancies and further enables the identification through distinct spectroscopic signatures of proton and fluorine local environments whose chemical shift values have been related to the different numbers of surrounding titanium and vacancies. Upon increasing the temperature the de-hydroxyfluorination of the lattice is accompanied by morphological changes via different mechanisms which identity/nature depends on the temperature. Up to $150{ }^{\circ} \mathrm{C}$, anisotropic crystal growth was observed and for $\mathrm{T}>150{ }^{\circ} \mathrm{C}$, both anisotropic and oriented attachment crystal growth have been observed. This study further proves the complexity of such a system and provides novel tools to optimize the material's properties by tuning the composition and morphology of nanoparticles.

\section{Experimental Section}

Synthesis. The synthesis method used is similar to our previous work in reference. ${ }^{[6]}$ Briefly, a solution containing $27 \mathrm{mmol}$ of HF (Rectapur, 40\%) and $25 \mathrm{~mL}$ of isopropanol (Sigma-Aldrich) was added to $13.5 \mathrm{mmol}$ of titanium isopropoxide ((Sigma-Aldrich) in a Teflon line container. Caution HF solution is highly hazardous and special protective equipments are required. The Teflon liner cup was placed inside a stainless stee autoclave and then heated in an oven at a desired temperature ranging from 110 to $190^{\circ} \mathrm{C}$ for $12 \mathrm{~h}$. After the reaction, the autoclave was left to cool down to room temperature. The resulting white precipitate was washed twice with ethanol and subsequently recovered by centrifugation at $4400 \mathrm{rpm}$ for $15 \mathrm{~min}$. Finally, the powder was dried at $80^{\circ} \mathrm{C}$ for $2 \mathrm{~h}$.

Characterization methods. X-ray powder diffraction analysis was carried out using a Rigaku Ultima IV X-ray diffractometer equipped with a $\mathrm{Cu} \mathrm{Ka}$ radiation source $(\lambda=1.54059 \AA)$. Transmission Electron Microscopy analysis was performed using a JEOL 2010 UHR microscope operating at $200 \mathrm{kV}$ equipped with a TCD camera.

Synchrotron diffraction data were collected at the 11-ID-B beamline at the Advanced Photon Source at Argonne National Laboratory, using high energy $X$-rays $(\lambda=0.2128 \AA$ ) allowing high values of momentum transfer.[20],[21] One-dimensional diffraction data were obtained by integrating the raw $2 \mathrm{D}$ total scattering data in Fit2D. ${ }^{[22]}$ PDFs, $G(r)$, were extracted from the background and Compton scattering corrected data following Fourier transformation using PDFgetX2. ${ }^{[23]}$ The PDFs were subsequently modelled using PDFgui. ${ }^{[24]}$

${ }^{1} \mathrm{H}$ and ${ }^{19} \mathrm{~F}$ solid-state magic angle spinning (MAS) NMR experiments were performed on a Bruker Avance 300 spectrometer operating at $7.0 \mathrm{~T}$ $\left({ }^{1} \mathrm{H}\right.$ and ${ }^{19} \mathrm{~F}$ Larmor frequencies of 300.1 and $282.2 \mathrm{MHz}$, respectively), using a $1.3 \mathrm{~mm}$ CP-MAS probe head. The room temperature ${ }^{1} \mathrm{H}$ and ${ }^{19} \mathrm{~F}$ MAS spectra were recorded using a Hahn echo sequence with an interpulse delay equal to one rotor period. The $90^{\circ}$ pulse length were set to $2 \mu \mathrm{s}$ and 1.55 (or 1.25) $\mu \mathrm{s}$ and the recycle delays were set to $10 \mathrm{~s}$ and $20 \mathrm{~s}$, for ${ }^{1} \mathrm{H}$ and ${ }^{19} \mathrm{~F}$, respectively. ${ }^{1} \mathrm{H}$ and ${ }^{19} \mathrm{~F}$ spectra are referenced to TMS and $\mathrm{CFCl}_{3}$, respectively and they were fitted by using the DMFit software. ${ }^{[25]}{ }^{19} \mathrm{~F}$ solid state NMR was used to quantify the fluorine content by using reference samples. ${ }^{[6,9,10]}{ }^{19} \mathrm{~F}$ solid-state MAS NMR (Hahn echo) spectra were also recorded for $\mathrm{YF}_{3}$ and $\mathrm{LaF}_{3}$ and the masses of each sample in the rotor were measured. The fits of the spectra allow to determine the integrated intensities (I) for each sample. Since, for each sample, the recycle delays were chosen to ensure that the amount of signal detected is maximum (420 s for $\mathrm{YF}_{3}$ and $120 \mathrm{~s}$ for $\mathrm{LaF}_{3}$ ), we assume that the integrated intensities are proportional to the number of scans (256 for the studied samples and 16 for $\mathrm{YF}_{3}$ and $\mathrm{LaF}_{3}$ ) and to the molar quantity of fluorine atoms $(n)$ in the rotor. This assumption is verified since the calculated $\mathrm{I} / \mathrm{n}$ ratio for $\mathrm{YF}_{3}$ and $\mathrm{LaF}_{3}$ are equal. The intensities per scan of the NMR signals of the studied samples, $I_{1}$, and of $\mathrm{YF}_{3}$ (or $\mathrm{LaF}_{3}$ ), $\mathrm{I}_{2}$, allow to calculate the fluorine wt. \% in the studied samples using the following formula where $\mathrm{m}$ and $\mathrm{M}$ are the mass and the molar mass, respectively:

$$
\begin{gathered}
\frac{I_{1}}{I_{2}}=\frac{n_{F}}{\frac{3 m_{Y F_{3}}}{M_{Y F_{3}}}} \\
F w t . \%=\frac{m_{F}}{m}=\frac{n_{F} M_{F}}{m}=\frac{3 m_{Y F_{3}}}{M_{Y F_{3}}} \frac{\mathrm{I}_{1}}{\mathrm{I}_{2}} \frac{\mathrm{M}_{\mathrm{F}}}{\mathrm{m}}
\end{gathered}
$$

\section{Acknowledgements}

The research leading to these results has received funding from the People Programme (Marie Curie Actions) of the European Union's Seventh Framework Programme (FP7/2007-2013) under REA grant agreement $\mathrm{n}^{\circ}$ [321879] (FLUOSYNES). S. Casale is acknowledged for HRTEM measurement. This research used resources of the Advanced Photon Source, a U.S. Department of Energy (DOE) Office of Science User Facility operated for the DOE Office of Science by Argonne National Laboratory under Contract No. DE-AC02-06CH11357.

Keywords: fluorolysis, oxy-hydroxyfluoride, oriented assembly, anisotropic crystal growth, ${ }^{1} \mathrm{H}$ and ${ }^{19} \mathrm{~F}$ NMR spectroscopy

[1] X. Chen, A. Selloni, Chem. Rev. 2014, 114, 9281.

[2] G. Liu, H. G. Yang, J. Pan, Y. Q. Yang, G. Q. (Max) Lu, H.-M. Cheng, Chem. Rev. 2014, 114, 9559

[3] H. G. Yang, C. H. Sun, S. Z. Qiao, J. Zou, G. Liu, S. C. Smith, H. M Cheng, G. Q. Lu, Nature, 2008, 453, 638.

[4] M. Lazzeri, A. Vittadini, A. Selloni, Phys. Rev. B, 2001, 63, pp 155409.

[5] X. Ma, Y. Dai, W. Wei, B. Huang, M.-H. Whangbo, J. Phys. Chem. Lett, 2015, 6, 1876.

[6] W. Li, D. Corradini, M. Body, C. Legein, M. Salanne, J. Ma, K. W. Chapman, P. J. Chupas, A.-L. Rollet, C. Julien, K. Zhagib, M. Duttine, A. Demourgues, H. Groult, D. Dambournet, Chem. Mater, 2015, 27, 50145019

[7] E. Kemnitz, U. Groß, S. Rüdiger, C. S. Shekar, Angew. Chemie Int. Ed, 2003, 42, 4251

[8] S. Rüdiger, E. Kemnitz, Dalton Trans, 2008, 1117

[9] W. Li, M. Body, C. Legein, O. J. Borkiewicz, D. Dambournet, Inorg. Chem. 2016, 55, 7182

[10] W. Li, M. Body, C. Legein, D. Dambournet, Cryst. Growth Des. 2016 DOI:10.1021/acs.cgd.6b00910.

[11] R. Menzel, A. Duerrbeck, E. Liberti, H. C. Yau, D. McComb, M. S. P. Shaffer, Chem. Mater. 2013, 25, 2137.

[12] X. H. Yang, Z. Li, C. Sun, H. G. Yang, C. Li, Chem. Mater. 2011, 23 3486.

[13] J. Pan, G. Liu, G. Q. (Max) Lu, H.-M. Cheng, Angew. Chem. Int. Ed. 2011, 50, 2133.

[14] Y. Luan, L. Jing, Y. Xie, X. Sun, Y. Feng, H. Fu, ACS Catal. 2013, 3, 1378.

[15] X. Han, Q. Kuang, M. Jin, Z. Xie, L. Zheng, J. Am. Chem. Soc. 2009, $131,3152$. 
[16] J. S. Chen, Y. L. Tan, C. M. Li, Y. L. Cheah, D. Luan, S. Madhavi, F. Y. C. Boey, L. A. Archer, X. W. Lou, J. Am. Chem. Soc. 2010, 132, 6124.

[17] K. W. Chapman, MRS Bull. 2016, 41, 231.

[18] J. Yu, G. Dai, Q. Xiang, M. Jaroniec, J. Mater. Chem. 2011, 21, 1049.

[19] M. Crocker, R. H. M. Herold, A. E. Wilson, M. Mackay, C. A. Emeis, A. M. Hoogendoorn, J. Chem. Soc. Faraday Trans. 1996, 92, 2791.

[20] P. J. Chupas, X. Qiu, J. C. Hanson, P. L. Lee, C. P. Grey, S. J. L. Billinge, J. Appl. Crystallogr. 2003, 36, 1342.

[21] P. J. Chupas, P. L. Lee, K. W. Chapman, J. Appl. Crystallogr. 2007, 40, 463.

[22] A. P. Hammersley, S. O. Svensson, M. Hanfland, A. N. Fitch, D. Hausermann, High Press. Res. 1996, 14, 235.

[23] X. Qiu, J. W. Thompson, S. J. L. Billinge, J. Appl. Crystallogr. 2004, 37, 678.

[24] C. L. Farrow, P. Juhas, J. W. Liu, D. Bryndin, E. S. Božin, J. Bloch, T. Proffen, S. J. L. Billinge, J. Phys. Condens. Matter 2007, 19, 335219.

[25] D. Massiot, F. Fayon, M. Capron, I. King, S. Le Calvé, B. Alonso, J.-O Durand, B. Bujoli, Z. Gan, G. Hoatson, Magn. Reson. Chem. 2002, 40, 70. 